this matter. These authors note that in the context of their (cross sectional) analysis of levels of $\mathrm{FEV}_{1}$ (as distinct from rate of loss in $\mathrm{FEV}_{1}$ with age) allowance for an age dependent smoking effect explained more of the total variability in their data than a simple additive model. They add, however, that the relationship between dust exposure and $\mathrm{FEV}_{1}$ was hardly altered by the way that smoking was taken into account. The latter finding is consistent with the results of other work, ${ }^{2}$ which show that the significant effect of dust exposure on $\mathrm{FEV}_{1}$ in coalminers who smoke is statistically indistinguishable from the dust effect evident in miners who do not smoke.

Dr Oldham is right in his assumption that the paper by Rogan et al which I mentioned is that published in the British Journal of Industrial Medicine (his reference 3) (and I am sorry about the error in my earlier lists of references). He is right also to point out that the analyses described in that paper did not, on their own, demonstrate the association between dust exposure and $F_{1} V_{1}$ separately in the 3005 men with category 0 . However, Dr Jacobsen, a coauthor of the paper, has in subsequent work on the same data confirmed the significant relationships between dust exposure and $\mathrm{FEV}_{1}$ in the 3005 men in category 0 (as well as in 2272 with no bronchitic symptoms, as first reported in $1973^{3}$ ). The negative gradient is evident and unlikely to be explicable by chance factors $(p<0.01)$ even in a small subgroup consisting of 346 life long non-smokers with radiographs classified as category $0 /-$ or $0 / 0$ who did not report having persistent cough and phlegm. A publication is being prepared giving details of these more recent studies of the material first reported by Rogan and his colleagues. ${ }^{3}$

I did not mention respiratory symptoms in my article or in the reply to comments, but since Dr Oldham raises the matter it is worth making two observations. Firstly, he chooses to discuss only one of three tables that show an association between dust exposure and the chronic cough and sputum syndrome in the two younger age groups studied by Rae et al (reference 4 cited by Dr Oldham). Secondly, both of the comments that he quotes from the paper are in the context of warnings that the apparent absence of the association in older men should not be interpreted as indicating that the effect of dust on symptom prevalence is minimal or non-existent.

Of course, no single report or study can provide the final answer to complex questions of this kind, and Dr Oldham is right to remind me of the caution required when attempting to draw conclusions from data subject to the selection effects so common in studies of industrial groups. In 1966 Professor Cochrane wrote "It is, I think, possible that if we could measure dust dosage more accurately then the correlation with respiratory symptoms and ventilatory function would be much more exact." ${ }^{3}$ Those more accurate measures of dosage have become available during the last 14 years as a result of the Coal Board's research. I was hoping that Professor Cochrane and his colleagues might now agree that the evidence accumulated vindicates his suggestion of 18 years ago. The correlations are now much more exact.

There is a danger that legitimate debate on the minutiae of individual reports will obscure an important point I was anxious to make. This was that a lot of new information is available now about relationships between direct measures of miners' exposures to dust and risks to their health, including the risk of developing disabling airways obstruction. That information has provided a rational basis for dust control strategies designed to protect the men's health.

ANTHONY SEATON

Institute of Occupational Medicine, Edinburgh EH8 $9 S U$

' Soutar CA, Hurley JF, Gurr DC. Relationship between dust exposure and lung function in miners and ex-miners. In: Proceedings of the VIth International Conference on Pneumoconiosis, Bochum 1983. Geneva: International Labour Office (in press).

${ }^{2}$ Jacobsen M. Occupational health risk assessment. In: Hester RE, ed. Industry and the environment in perspective. London: Royal Society of Chemistry, 1983:179-89. (Special Publication No. 46.)

${ }^{3}$ Cochrane AL. Chronic bronchitis and occupation. Br Med J 1966;i:858-9.

\section{Persisting "asthma" in tropical pulmonary eosinophilia}

SIR,-We were very interested in the report by Dr DA Jones and his colleagues (September 1983, p 692) of tropical pulmonary eosinophilia simulating classical asthma in a 37 year old Indian man.

We met the same problem in a 4 year old Indian girl who had been resident in France for one year. She was referred to our paediatric chest clinic with the diagnosis of asthma of two months' duration. After four months of oral bronchodilator treatment only partial improvement had been achieved and our attention was drawn to the unusual intensity of inspiratory crackles audible in the chest and to a leucocytosis varying from 8.2 to $22.4 \times 10^{9} / 1$ with $24-60 \%$ of eosinophils. The total serum immunoglobulin $E$ concentration was $940 \mathrm{IU} / \mathrm{ml}$ (PRIST Phadebas). The chest radiographs were reviewed and found to show diffuse bilateral miliary mottling, predominant in the mid and lower zones. The filarial fluorescent antibody (FFA) test gave a positive result with a titre of $1 / 12800$. Specific dynamic compliance was decreased $\left(48 \mathrm{ml} / \mathrm{cm} \mathrm{H}_{2} \mathrm{O} / \mathrm{l}\right.$ at functional residual capacity; normal $=68) .{ }^{1}$ Intradermal skin test responses to common inhaled allergens were negative.

During treatment with diethyl carbamazine in a total dose of $2 \cdot 1 \mathrm{~g}(123 \mathrm{mg} / \mathrm{kg})$ over 22 days, the serum $\mathrm{IgE}$ concentration peaked at $19900 \mathrm{IU} / \mathrm{ml}$ and was still raised at $1100 \mathrm{IU} / \mathrm{ml}$ one year later. One month after completion of treatment the result of the FFA test was positive with a titre of $1 / 200$, but specific dynamic compliance had returned to normal values. Chest radiographs showed clearing of the mottling six months after treatment had started, although blood eosinophilia persisted $\left(1.1 \times 10^{4} /\right.$ 1). Dyspnoea disappeared within a few weeks of starting treatment with diethyl carbamazine and bronchodilator drugs were discontinued. There has been no recurrence of symptoms during the three years that have followed.

Tropical pulmonary eosinophilia is exceedingly rare in 
childhood. ${ }^{2}$ The diagnosis should nevertheless be suspected in a child coming from an endemic area, particularly where there is a very high blood eosinophilia count and a diffuse reticulonodular pattern on successive chest radiographs. $^{3}$

J DE BLIC

P SCHEINMANN

J PAUPE

Service de Pneumologie et Allergologie Infantiles

Département de Pédiatrie

Hôpital des Enfants Malades

Paris

alades

Paris

' Jean R, Benoist MR. In: Exploration fonctionnelle pulmonaire en pédiatrie. Paris: Flammarion, 1979.

${ }^{2}$ Udwadia FE. In: Hertzog $\mathrm{H}$, ed. Progress in respiration research-7. Basel: Karger, 1975:35.

${ }^{3}$ Fraser RG, Paré JA. Diagnosis of diseases of the chest. Vol 2. Philadelphia: WB Saunders, 1978;864-5

Partial anomalous pulmonary venous return with intact atrial septum: report of four cases

SIR,--In their interesting paper concerning partial anomalous pulmonary venous connection with intact atrial septum (November 1983, p 859) Dr JR Stewart and his colleagues state "In the absence of an interatrial communication ... the condition is uncommon." I wonder what evidence they have for making this statement? In a paper published by Hughes and Rumore as long ago as 1944,' the authors commented "The incidence of this condition cannot be estimated." None the less, among the 280 cadavers examined by them two cases of partial anomalous pulmonary venous connection were found, giving an incidence of $0.7 \%$. They also pointed out that Adachi had found an exactly similar incidence in 1933.

The final point of this paper is that "no trustworthy estimation can be made of the incidence of anomalous pulmonary veins." However, their experience would suggest that they are not as uncommon as Dr Stewart and his colleagues suggest. It is also of interest that their second patient had azygos continuation of the inferior vena cava. This should raise the suspicion of left atrial isomerism (polysplenia). Do the authors have any information about the atrial arrangement in this patient? Surely this important condition should be listed among the associated lesions mentioned by the authors?

Cardiothoracic Institute and Brompton Hospital
London SW3 $6 H P$

' Hughes CW, Rumore PC. Anomalous pulmonary veins. Arch Pathol 1944;37:364-6.

***This letter was sent to Dr Stewart, who replies below.

SIR,-We thank Professor Anderson for his interesting comments. There is indirect evidence about the rarity of partial anomalous pulmonary venous connection with intact atrial septum. We perform approximately 1300 cardiac catheterisations per annum at this institution and have seen this lesion only four times since 1970. During the same time interval we have corrected 111 atrial septal defects with partial anomalous pulmonary venous connection. It is interesting to note that in the combined experience of the Johns Hopkins Hospital and Massachusetts General Hospital there have been only eight reported cases, most in association with mitral valvular disease. However, as we stated in the article, "a single anomalous vein with an intact atrial septum is probably clinically unimportant and may account for the rarity of reported cases." Inherent bias clouds all necropsy and cardiac catheterisation series, and we would strongly concur with Hughes and Rumore that no accurate estimation of the incidence of this lesion can be proposed.

We have no further information about the atrial arrangement of the patient with azygos continuation of the inferior vena cava, but agree that it is possible that he did indeed have left atrial isomerism. We are grateful to Professor Anderson for pointing out this omission.

JAMES R STEWART Department of Surgery Johns Hopkins Hospital Baltimore, Maryland, USA 